Referencia:

van Diest, Camila. "Imaginación oficial y espacios culturales en Chile: Reflexiones en torno al caso Niemeyer", Revista Austral de Ciencias Sociales, vol. 26, p.83-102, 2014.

URL: http://mingaonline.uach.cl/scielo.php?pid=S0718-17952014000100005\&script=sci_arttext

\title{
Imaginación oficial y espacios culturales en Chile: \\ Reflexiones en torno al caso Niemeyer
}

\author{
Official Imaginary and Cultural Places in Chile: \\ Reflections on the Niemeyer case
}

Camila van Diest ${ }^{1}$

\section{Resumen}

El año 2007, la ciudad de Valparaíso recibe un regalo del arquitecto brasileño Oscar Niemeyer. Se trataba de un boceto de centro cultural, planeado para ser construido en los terrenos del Parque cultural Ex cárcel de Valparaíso. Aunque el proyecto nunca llegó a ser implementado, abrió un importante debate en la esfera pública chilena. El fuerte contraste entre el estilo arquitectónico del proyecto y las características de la ciudad, así como la escasa incorporación de la opinión de la comunidad y las organizaciones locales, fueron denunciadas desde el comienzo por los actores involucrados. Por otro lado, se esperaba que la obra del renombrado arquitecto legitimara simbólicamente la ciudad, favoreciendo el turismo y revitalizando la economía.

Tomando en cuenta las lógicas de marketing urbano que afectan Valparaíso, el objetivo de este trabajo es analizar de qué modo la promoción oficial del centro cultural concebido por Oscar Niemeyer se relaciona con un paradigma implícito en la concepción concertacionista de la cultura.

\section{Palabras claves}

Imaginario, política cultural, infraestructura cultural, Ex - cárcel de Valparaíso, Óscar Niemeyer.

\section{Abstract}

\footnotetext{
${ }^{1}$ Université Sorbonne Nouvelle, Paris 3. CERLIS UMR 8070 Sorbonne Nouvelle / Paris Descartes / CNRS.
} 
In 2007, the city of Valparaiso (Chile) received a donation from the Brazilian architect Oscar Niemeyer. It was a blueprint for a cultural centre, planned to be built on the grounds of the "Former prison cultural park". However, the project never succed to be implemented, opening a long debate within the Chilean public sphere. The striking contrast between the project's architectural style and the city's architectural characteristics and the neglect of the opinion of local communities and grassroots organizations, were denounced from the start by the actors involved. On the other hand, it was expected that the brainchild of the renowned architect would simbolically legitimise the city, encourage tourism and revitalise its economy.

Taking into account the urban marketing dynamics involved in Valparaíso, the aim of this work is to analyze how the official promotion of the cultural center conceived by Oscar Niemeyer is related with an underlying paradigm of the concertacionist conception of culture.

\section{Keywords}

Imaginary, cultural policies, cultural infrastructure, Valparaiso's former prison, Oscar Niemeyer, 


\section{Imaginación oficial y espacios culturales en Chile: Reflexiones en torno al caso Niemeyer}

El proyecto donado a Valparaíso por el arquitecto brasileño Oscar Niemeyer, desde su acotada permanencia en el debate público entre los años 2007 y 2008, constituye un buen punto de partida para interrogar críticamente el modo en que las tensiones de la cultura se despliegan en el contexto chileno de comienzos de siglo XXI. Aun cuando se trata de un proyecto fallido, que nunca se concretó, éste se enmarca en el desarrollo de un proceso más amplio que ilumina algunos aspectos poco tematizados del pensamiento de la cultura predominante en el Chile concertacionista: La reconversión del antiguo penal porteño en espacio cultural a partir del año 2000.

Este trabajo tiene como objetivo indagar en qué medida la promoción oficial en Chile del centro cultural ideado por Oscar Niemeyer moviliza un paradigma implícito en la concepción de la cultura impulsada por los gobiernos de la Concertación.

Para ello, el artículo se organiza en dos partes. En primer lugar, nos dedicamos a trazar las claves teóricas en que se enmarca nuestro análisis y a identificar ciertos procesos locales que permiten situar el proyecto Niemeyer para la Ex Cárcel. En segundo lugar, proponemos tres aproximaciones interpretativas de los discursos públicos producidos en torno al proyecto, a partir de una análisis de artículos de prensa.

\section{Introducción y aproximaciones teóricas}

Resulta importante delimitar brevemente aquí algunas claves conceptuales del modo en que retomamos la noción de imaginario, en el contexto del problema específico que nos ocupa. Se trata sin duda de un concepto polisémico que ha sido esgrimido desde distintos frentes de las ciencias sociales, en el marco de temáticas y objetivos disímiles, por lo que nuestro propósito no será el de una revisión teórica exhaustiva.

En su trabajo "La institución imaginaria de la sociedad" (1975) Cornelius Castoriadis teoriza a partir de una crítica al marxismo y al funcionalismo ${ }^{2}$. Señala aquí que, como

\footnotetext{
${ }^{2}$ Inscribiéndose en una "filosofía de la praxis" en auge desde mediados de los años '60, según J. Habermas "la obra de Castoriadis ocupa un lugar central. Constituye la tentativa más original, más ambiciosa y más meticulosa para continuar pensando como praxis una mediación emancipatoria entre la naturaleza- interna y externa- , la
} 
producto de una creación colectiva anónima, los imaginarios se inscribirían histórica y socialmente, pudiendo ser entendidos como una invención social radical que permitirían representarse una relación o una cosa que no han sido o no pueden ser aprehendidas bajo el modo de la percepción (1999).

Conviene detenernos brevemente en los planteamientos de este autor, particularmente en su crítica a una perspectiva funcionalista, a la que considera insuficiente como marco teórico para entender la institución. Si bien las instituciones "cumplen funciones", Castoriadis advierte que no pueden ser reducidas a ese fin; al mismo tiempo, desde una perspectiva instrumental de adecuación de medios a fines, no existiría ningún criterio sustantivo para discernir las "necesidades últimas" a las que las instituciones vendrían a dar respuesta. Las instituciones, señala Castoriadis, se expresarían en el modo de "lo simbólico", es decir, que "existen socialmente como sistemas simbólicos sancionados. Consisten en asociar a símbolos (significantes), significados (representaciones, órdenes, incitaciones a hacer o a no hacer, consecuencias - significaciones, en el sentido amplio del término) y a hacerlas valer como tales, es decir, a hacer esta ligazón más o menos forzada para la sociedad o el grupo considerado" (1999, 174-175).

Sin embargo, este entramado simbólico como base de la institución, no bastaría para comprender la transformación y la capacidad instituyente - la constante creación de sentidoen un plano social-histórico. Es ante esto que el concepto de imaginario cobra fuerza y adquiere su real dimensión para el autor, en la medida que posibilita la emergencia de lo nuevo, es decir, el surgimiento de otros modos de vinculación (no instituidos) entre significantes y significados, movilizando así la transformación más allá de la permanencia y la reproducción social asegurada por el simbolismo. Ambas nociones- imaginario y simbolismo- serían de este modo complementarias y se encontrarían en mutua implicación, poniendo la primera el acento en la emergencia de lo nuevo- los procesos instituyentes- y la segunda en el orden- lo ya instituido. De esta manera, señala que las sociedades habrían "encontrado su fuente en el imaginario social. Este imaginario debe entrecruzarse con los

sociedad y la historia”. Habermas, Jurgen. 2011. Le discours philosophique de la modernité: douze conférences. Paris: Gallimard, p. 387. Traducción de la autora (Esta precisión se aplica a todos los textos originalmente en francés e inglés citados en este trabajo). 
simbólico, de otro modo la sociedad no habría podido 'reunirse', y con lo económicofuncional, de otro modo ella no habría podido sobrevivir" (Castoriadis 1999, 197).

Aunque profundizar en la noción de imaginario permitiría extendernos a los mitos y leyendas, a los procesos cognitivos o a una sociología de la vida cotidiana (entre otros), para el horizonte de este trabajo resulta pertinente entenderlo a partir de estas claves, que según lo antes dicho podríamos resumir en la fórmula de "la imaginación de una sociedad otra" (Cit. en Legros et al. 2006, 3): una perspectiva de la imaginación que "no cesa de atravesar los proyectos y ensayos de transformación social" (Sironneau, 27).

Ahora bien, es preciso aquí hacer ciertas precisiones sobre el cariz utópico que comportan estas formulaciones, y sus posibles alcances más concretos. Según Baczko, lejos de ser sólo representaciones consensuales los imaginarios se perfilan también como "piezas efectivas y eficaces del dispositivo de control de la vida colectiva, y especialmente del ejercicio del poder" (Baczko 1984: 33). Se trataría así de territorios de disputa que, tal como se desprende de lo formulado por Castoriadis, no "reflejan" una realidad preexistente, no son una "imagende" otra cosa, pero se entraman a una multiplicidad de lenguajes y pueden, de este modo, comportar efectos reales: "el imaginario no se opone aquí a la realidad como ficción inconsistente, sino que estructura esta realidad social incluso en sus aspectos más concretos" (Vanni 2006, 152). Siguiendo a Baczko, en su análisis de los imaginarios bajo el prisma de la utopía y la memoria (1984) resulta entonces importante el matiz: el imaginario no se restringiría únicamente a una voluntad radical emancipatoria y sin duda, nada obligaría a que aquella "sociedad otra", constituya, desde cualquier punto de vista, "una sociedad mejor".

Es preciso referirnos también a la distinción entre imaginario e imaginación, que introducimos desde el título de este trabajo. Con esto, básicamente, buscamos marcar una distancia ante la respuesta que Castoriadis otorga a la pregunta por el "sujeto" de esta imaginación: si en el caso del autor, el sujeto portador de dichos imaginarios no sería un individuo ni un sujeto específico, sino que correspondería a una instancia colectiva y anónima

\footnotetext{
${ }^{3}$ Así también lo entiende Jean-Pierre Sironneau, al reflexionar sobre los conceptos afines de ideología y utopía. El autor destaca el carácter "demasiado estático y demasiado rígido de la oposición ideología- utopía. Las formas de la imaginación colectiva no son todas reducibles a estos dos polos que no son, en definitiva, más que polos ideales: hay muchos tipos de utopías como hay muchos tipos de milenarismos. Por lo demás, se trata de dos direcciones fundamentales del imaginario social, ellas se implican dialécticamente y no son extranjeras una a la otra" (Sironneau, 1993, 40).
} 
(Vanni 2006), consideraremos aquí la imaginación más bien ligada al ejercicio del poder, en tanto nuestro interés se dirige prioritariamente hacia la vertiente oficial de los discursos en torno al proyecto arquitectónico de Oscar Niemeyer. Para Adrián Gorelik, en ese sentido, la imaginación urbana correspondería a un ámbito más restringido que aquél del imaginario, y podría entenderse "como una dimensión de la reflexión político-técnica (por lo general, concentrada en un manojo de profesiones: arquitectura, urbanística, planificación), acerca de cómo la ciudad debe ser" (Gorelik 2004). A este horizonte de expectativas con una clara orientación normativa, es importante agregar la necesaria puesta en circulación pública- y la correspondiente promoción oficial- de tales proyectos o reflexiones.

En ese sentido, aunque empleemos alternativamente los términos imaginario e imaginación, las lecturas que aquí desarrollamos dejan más bien entre paréntesis las representaciones y anhelos de los ocupantes de la Ex - cárcel, de los habitantes de barrios aledaños o de los eventuales públicos de este espacio: se trata de una aproximación exploratoria que forma parte de un proyecto mayor ${ }^{4}$ :

A partir de este marco, nos proponemos desarrollar una lectura cruzada entre el "Proyecto Niemeyer" para la Ex - cárcel de Valparaíso, y ciertos principios a la base de las políticas culturales nacionales durante el período de los gobiernos de la Concertación en Chile (especialmente el período entre 2000 y 2009). Esto nos obliga a leer entre líneas, pues de hecho es sólo a partir de segundas lecturas que podemos asociar la gestión del proyecto a una política cultural tácita. En efecto, hasta bastante avanzado el conflicto, su tematización política y la configuración de una escena pública en torno a él (Quéré 1992), permanecieron más bien desligadas de los debates sobre "lo cultural", asociándose prioritariamente a dilemas relativos a la gestión urbana local. Esto sugiere principalmente que el fenómeno que se desencadena con este proyecto desborda hacia distintos dominios, y que sus alcances no se circunscriben a los discursos públicos más perceptibles, ni tampoco a las bulladas polémicas que en ese momento se entretejieron en torno a él.

Para abordar la puesta en contexto de la Ex - cárcel, es necesario revisar algunos rasgos de las políticas culturales que comienzan a implementarse desde la década de los ‘90.

\footnotetext{
${ }^{4}$ Este trabajo es parte de mi tesis doctoral en Sociología, en la Universidad Sorbonne Nouvelle - Paris 3/ Laboratorio CERLIS, actualmente en curso.
} 
En primer lugar, habría que destacar la aspiración a una "autonomía" de la esfera artística y cultural, y más precisamente, de las nacientes estructuras institucionales de la cultura postdictadura. La autonomía aparece como una como una meta a alcanzar que permitiría superar las condiciones represivas instaladas en dictadura, cuyas consecuencias fueron en general comprendidas bajo la fórmula del "apagón cultural" (Garretón 1993). Esta idea cobra fuerza en los discursos y es enarbolada por distintos actores como una de las bases necesarias para un desarrollo democrático en el ámbito de la cultura, subrayándose como uno de los nortes de la institucionalidad que comienza a configurarse con el Fondo Nacional de Desarrollo de las Artes (FONDART), en 1992, y luego con la creación del Consejo Nacional de la Cultura y las Artes (CNCA), en 2003. La discusión sobre la autonomía se vinculará en un sentido más amplio a un debate sobre el rol del Estado respecto a la cultura.

Se asume así una política "formal", que- desde el principio de una "neutralidad ética" del Estado- garantice la pluralidad de oportunidades y la equidad de la distribución de recursos a partir de ciertos "arreglos institucionales básicos” (Sunkel y Catalán 1993). Así por ejemplo, en 2003 la perspectiva oficial considera que el Estado no debe "dirigir la cultura de un país, pero tampoco debe estar ausente de ella" (Lagos 2003).

Un segundo elemento relevante es el énfasis puesto en las nociones de desarrollo y progreso. Es interesante detenerse en ellas brevemente, pues parecen sintetizar ciertos elementos propios de las políticas culturales durante la Concertación que repercutirán en el devenir de la Ex - cárcel. Así por ejemplo, en el documento institucional "Chile quiere más cultura. Definiciones de política cultural 2005-2010" (CNCA 2005), la cultura es, por una lado, asociada a valores humanistas y educativos, pero también, por otro, a la idea de "valor agregado". Se advierte allí que

en las economías modernas, la especificidad artística de los productos, el diseño, la publicidad y el marketing, se han convertido en un valor agregado significativo, lo que convierte a la cultura en un valor y una ventaja para los países y las empresas en su capacidad competitiva. Por eso podemos afirmar que el arte y la cultura iluminan al país y son factores decisivos en su proyección al futuro. (CNCA 2005: 12)

Este documento, que define los lineamientos en políticas culturales a seguir a partir de 2005, señala también que "la tarea creativa es autónoma y autosuficiente" (CNCA: 18), y establece una ligazón estrecha entre patrimonialización e internacionalización, diagnosticando 
que "en Chile existe una carencia importante de cultura patrimonial, que afecta la construcción de nuestra identidad y mina nuestra proyección en la comunidad internacional" (CNCA: 26). La cultura se destaca así como factor de inserción de Chile en un escenario global, que se esboza reiteradamente como horizonte.

La configuración de las políticas culturales post 1990 se encuentra inscrita en el contexto más general y omnipresente del modelo económico neoliberal, implantado en Chile desde la dictadura, y cuyos principios se dejan ver de modo más o menos claro, más o menos coherente, en los elementos antes mencionados. Ya para ese momento bien consolidado, este modelo no sólo atraviesa lo propiamente social, económico y político, sino que constituye también una trama cultural, instalándose en los discursos y en los modos de imaginar el país (Cárcamo-Huechante 2007). Esta infiltración de un discurso de mercado en la trama culturaldel que la categoría de "valor agregado" ciertamente parece elocuente- sumado al ejercicio de una "política de consensos" (Drake y Jaksic 1999: 16) autonomía que antes señalamos, logrando permear los modos de concebir la cultura y sus espacios durante el período, muchas veces de manera implícita.

En este marco, y más allá de la definición programática de las políticas culturales, habría que subrayar el despliegue de una lógica de recurso (Yúdice 2002): Desde esta perspectiva la cultura es entendida como un medio para múltiples fines, y en esa medida las políticas culturales movilizan intereses no necesariamente culturales. Yúdice enfatiza así "el carácter instrumentalista de la política cultural de hoy" (2002: 41), que recubriría sus consideraciones más técnicas.

De este modo, estas políticas no serán exclusivamente impulsadas por los organismos formalmente designados para ello, sino que podrían ejercerse desde un poder débil (Ahearne 2009: 143). Ahearne introduce así el matiz entre políticas culturales explícitas e implícitas, proponiendo liberar la perspectiva sobre las políticas culturales de un extremo nominalismo:

\footnotetext{
${ }^{5}$ Respecto a esta noción, los autores sostienen que "la Concertación encontró obstáculos insuperables para modificar de manera sustancial el modelo económico y hubo de optar por una política de consenso antes que de enfrentamiento con la derecha. Aun así, logró triunfos importantes, como la reforma impositiva que hizo posible un aumento del gasto social. Al mismo tiempo, los trabajadores organizados eran ahora mucho más débiles frente a los empresarios, de modo que no existía una base social o política para una línea populista y mucho menos socialista. Cuarto, la favorable situación económica de los noventa militaba contra cualquier desvío de la ruta trazada por Pinochet. Quinto, el clima internacional a favor de las reformas económicas neoliberales y las democracias prudentes hacía difícil cualquier cambio radical” (Drake y Jaksic 1999: 16-17).
} 
Explícitas o implícitas, éstas movilizan intereses, extraen recursos y se perfilan simultáneamente como una política simbólica, conducente a modelar el imaginario al “orientar el espíritu público en su sentido más amplio, o sea como producción, difusión, distribución y consumo de objetos y formas simbólicas" (Rodríguez 2001: 406). Las políticas dirigidas a favorecer el desarrollo de las prácticas artísticas podrán entonces también orientarse hacia la promoción y la propaganda en múltiples niveles: de una ciudad, de un país, de la "identidad nacional", de un gobierno o autoridad específica.

La preocupación por entrar de lleno en los procesos de globalización, y especialmente la mirada hacia la cultura como bisagra entre lo local y lo global, es así un tercer punto que debiéramos considerar respecto a las políticas culturales, transversal del período de los gobiernos de la Concertación, y de esta "imaginación oficial" a la que nos referimos. El gobierno de Ricardo Lagos resulta aquí determinante, en la medida que "uno de sus grandes esfuerzos se produjo en la inversión en infraestructura (...), presentada en sus discursos como una de sus grandes obras" (Fazio 2006: 26).

Comenzando la década del 2000, Lagos recién elegido funda una Comisión de Infraestructura cultural: el importante énfasis puesto en este ámbito, así como la instalación en 2003 del CNCA en Valparaíso, sugieren que lo cultural estará con frecuencia inscrito en debates sobre el uso e incluso los alcances simbólicos del espacio (en términos arquitectónicos, infraestructurales, urbanos, de localización geográfica, etc. $)^{6}$. Pero es en la ciudad-puerto donde dichas formulaciones cobran ribetes paradigmáticos, a través del despliegue de lo que podría ser visto como una "ideología patrimonialista" (Sobarzo 2009: 51). Al respecto, es necesario recordar que desde el año 1997 un sector de la ciudad era postulada a la lista del Patrimonio de la Humanidad por la Unesco, inclusión que finalmente será obtenida en 2003. Ese mismo año la ciudad es también investida con el título inédito de "capital cultural" de Chile.

Este proceso de patrimonialización, como lo señalan Aravena y Sobarzo (2009), debe entenderse en relación a la progresiva desarticulación del trabajo industrial portuario,

\footnotetext{
${ }^{6}$ Recordemos que durante este período se inauguran las "fiestas de la cultura"- donde destacan los "Carnavales culturales" impulsados por el CNCA, realizados anualmente en Valparaíso. También durante estos años crea el Centro cultural Palacio La Moneda en Santiago.
} 
enmarcada en una tendencia mundial ligada a la expansión de "nuevas lógicas del capital". De este modo,

La proyección de Valparaíso, o parte de él, como Patrimonio de la Humanidad, marca -por parte de las autoridades de turno- una definición de la estrategia de desarrollo de las zonas que han visto extinguirse sus tradicionales actividades económicas (...). Es el caso en Chile no sólo de Valparaíso y su aminorada actividad portuaria, sino también de ciudades del Norte Grande, como Iquique o Antofagasta respecto de la extracción salitrera, o Lota luego de la muerte decretada de la minería del carbón. Todas, desde luego, señaladas hoy como zonas de alto "valor patrimonial". No es casual que en todos estos casos se trate de nuestra sudaca versión de explotación industrial, de esas antiguas formas de trabajo que engendraban sus correspondientes antiguas relaciones sociales. Ser patrimonio es el destino postindustrial de Valparaíso. (Aravena y Sobarzo 2009: 14)

También consideradas como una "barcelonización” de la ciudad (González 2010) es decir, el intento de replicar un modelo de desarrollo implementado en la ciudad catalana, estas estrategias han seguido una lógica de investiduras patrimoniales, promoción del turismo, fomento de las industrias culturales, terciarización, marketing urbano y especulación inmobiliaria. En ese mismo sentido, Harvey (2002) ha propuesto entender este proceso a través del concepto de "capital simbólico colectivo". Retomando los planteamientos bourdianos, según esta noción se entiende que las ciudades compiten por acumular marcas de distinción en un escenario global, donde el "poder del capital simbólico colectivo, de marcas especiales de distinción que se adhieren a un lugar (...) tienen un poder definitorio significativo sobre los flujos de capital en un sentido más general” (Harvey 2002: 103).

Podemos notar que son aquí los lugares- o la ciudad- los que se agencian aquello que Bourdieu entendía a una escala individual. Si el capital simbólico se fundamenta básicamente en una creencia, y "sustrae a la insignificancia, como ausencia de importancia y de sentido" (Bourdieu 1997: 285), podríamos entonces considerar el capital simbólico de los lugares como aquello que les permite saltar a un reconocimiento, escapando a su irrelevancia en un contexto global o, parafraseando al sociólogo francés, a una "existencia sin justificación". Los valores patrimoniales se perfilarían así como una de esas "marcas de distinción" que fundamentarían el "valor agregado" al que ya más arriba hacíamos mención.

Finalmente, la inminencia del Bicentenario de la independencia, en Chile, tendrá alcances directos para el contexto general de la promoción del proyecto de Oscar Niemeyer y las tensiones por el destino de la Ex - cárcel. Es interesante recordar que esta situación es 
compartida con otros países de la región (Argentina, Bolivia, Colombia, Venezuela, México, Paraguay, entre otros), y que cada cuál pondrá distintos acentos en sus celebraciones nacionales. De esta manera, si "en general, las iniciativas del Bicentenario buscan producir de cierta forma un impacto positivo en la gobernabilidad urbana, que estratégicamente trata de dar cuenta de la estabilidad en las dimensiones político-económica y socio-cultural" (Sepúlveda Ocampo et al 2009: 33), en el caso de algunos países esto se vinculó especialmente a la recuperación de la identidad colectiva y la memoria histórica ${ }^{7}$. En el caso chileno, el mismo año de su llegada a la Moneda, Ricardo Lagos creará también la Comisión Bicentenario, orientada a la preparación de las celebraciones para 2010. Los "Proyectos Bicentenario" en Chile, por lo general de alta envergadura y presupuesto,

se concentran principalmente en el enfoque cultural y científico - tecnológico, pensando en el fortalecimiento de la marca-país. Probablemente por esa razón se perciba una marcada predominancia de las propuestas en la ciudad capital y principalmente en obras físicas, al estar orientadas a asignar una mayor visibilidad a la nación dentro del contexto de los países en conmemoración de la Región, a enfatizar una postura más futurista; es decir, de lo que se espera mañana, con menos énfasis en rememorar la historia y el pasado del país. (Sepúlveda Ocampo et al 2009: 27-28)

Dentro los "Proyectos Bicentenario" sólo algunos de ellos fueron considerados "Proyectos país", destacando por su carácter cultural el Centro Gabriela Mistral (GAM), el Museo de la Memoria y los Derechos Humanos y, por cierto, el Parque cultural Ex - cárcel de Valparaíso.

Desde esta tensión entre pasado y futuro, la proyección de una imagen de la ciudad de Valparaíso quedará inmersa en una prolífica trama de discursos sobre el desarrollo, la infraestructura cultural, las tentativas de renovación urbana, la memoria, el patrimonio y su modelo de gestión, así como los alcances reales de la participación ciudadana. En estos términos, puede ser considerada como un lugar paradigmático del discurso institucional sobre la cultura de estos años, como también de sus contradicciones.

\footnotetext{
${ }^{7}$ Argentina, Paraguay y Colombia, principalmente (Sepúlveda Ocampo et al 2009).
} 


\section{Metodología}

La segunda parte de este trabajo indaga los principales tópicos que emergen en los discursos torno al proyecto Niemeyer. Antes de ello, conviene precisar los principales supuestos y procedimientos metodológicos que guiaron este trabajo.

La decisión de concentrarnos en los discursos de prensa - dejando de lado un abundante material de entrevistas en profundidad - responde fundamentalmente a que nuestro interés se centra aquí en los discursos públicos, poniendo provisoriamente entre paréntesis el modo en que los actores involucrados de primera mano en la Ex -cárcel relatan retrospectivamente sus experiencias en el lugar. Entendiendo que "las ideologías y las opiniones de los periódicos generalmente no son personales, sino sociales, institucionales o políticas" (van Dijk 1996: 9), los medios informativos constituyen uno de los soportes privilegiados de este tipo de discursos, contribuyendo tanto a su difusión como a la reproducción social de imaginarios dominantes.

Para realizar el análisis, elegimos dos periódicos de distribución regional: los diarios El Mercurio de Valparaíso y La Estrella de Valparaíso, ambos pertenecientes a la empresa El Mercurio Sociedad Anónima periodística. La selección de estos medios se realizó en base a dos supuestos: En primer lugar, el de la escasa cobertura del acontecer regional en la prensa nacional (Stambuk 1999; Jiménez y Muñoz 2011 ), lo que nos llevó a privilegiar diarios regionales.

El segundo supuesto, reconoce que la estructura de los medios en Chile puede caracterizarse como altamente concentrada en dos consorcios periodísticos, donde "la mayor parte de los medios pertenecen a reducidos grupos de carácter oligopólico que, desde la capital del país (Santiago) controlan el mercado de la prensa, la radio y la televisión” (Jiménez y Muñoz 2009). Resulta pertinente asumir entonces que en los medios seleccionados, pertenecientes al grupo empresarial encabezado por Agustín Edwards, se expresaría preferentemente la promoción oficial del proyecto Niemeyer, en contraste con medios alternativos de prensa local. Esto en la medida que el discurso periodístico de estos diarios puede identificarse con la ideología neoliberal dominante en Chile, y que las hipótesis 
preliminares de este estudio sugieren que la promoción del proyecto del arquitecto brasileño en Chile se sostiene implícitamente en esta misma lógica ${ }^{8}$.

La revisión de prensa se desarrolló en la Biblioteca pública Santiago Severín entre los meses de marzo y mayo de 2013. Los períodos revisados fueron: mayo de 2007, octubre de 2007 a enero de 2008; marzo a mayo de 2008 y noviembre a diciembre de $2008^{9}$. Se tomó en cuenta la totalidad de las secciones de los diarios- incluidas columnas de opiniónconsiderando los artículos según su referencia al proyecto de Oscar Niemeyer, o a eventos significativos ocurridos durante el mismo período en la Ex cárcel y que se vincularan al contexto mayor de la promoción de la propuesta del arquitecto. Bajo este proceder se conformó un corpus de 38 notas de prensa: 22 de ellas corresponden a El Mercurio de Valparaíso y 16 a La Estrella de Valparaíso, tal como se especifica en la tabla anexa ${ }^{10}$.

Complementariamente, se realizó una revisión no exhaustiva de medios en soporte digital, particularmente la versión electrónica de los diarios La Nación, La Tercera, y el sitio web www.plataformaurbana.cl. El criterio de búsqueda utilizado fue igualmente la alusión al proyecto de Niemeyer para la ex cárcel, y la condición de que los artículos hubieran sido publicados originalmente entre los años 2007 y 2008. A su vez, tomamos en cuenta documentos producidos por los propios ocupantes en el marco de las controversias por la ocupación y futuro de la Ex cárcel.

Es importante remarcar que nuestro propósito aquí no es elaborar una síntesis panorámica de los tópicos que presenta la producción periodística durante los años en que se debate el proyecto Niemeyer. En ese sentido, nuestros resultados no pretenden ser generalizables a la totalidad del discurso periodístico sobre este caso. Bajo la hipótesis de que este último se vincula a un pensamiento sobre la cultura durante los gobiernos de la Concertación, y de que

\footnotetext{
${ }^{8}$ Esto sin perjuicio de que tanto El Mercurio de Valparaíso como La Estrella de Valparaíso otorguen también cobertura a las críticas al proyecto: tal como puede apreciarse en los títulos detallados en la tabla anexa, efectivamente esto se constata abundantemente en el corpus revisado.

${ }^{9}$ La selección de estos períodos se realizó según la información que disponíamos previamente sobre hitos claves en este proceso, a partir de un seguimiento realizado durante los mismos años en que se desarrollaron los hechos. Los hitos en cuestión fueron: las primeras negociaciones para el proyecto de Niemeyer en Valparaíso (mayo de 2007), la irrupción del proyecto en el debate público (octubre de 2007); el cierre forzado de la cárcel (marzo de 2008) y la paralela denuncia de una serie de incendios por parte de los ocupantes y, por último, el descarte final del proyecto (noviembre de 2008). En ese sentido, optamos por revisar la prensa correspondiente a los meses en que ocurrieron estos eventos, así como los meses anteriores o sucesivos.

${ }^{10}$ Este corpus, dados los criterios que se especifican, es de carácter no- selectivo: incluye la totalidad de documentos encontrados en El Mercurio de Valparaíso y La Estrella de Valparaíso durante los meses precisados.
} 
los medios de prensa escrita son un dispositivo protagónico de la circulación y legitimación de los discursos públicos, lo que buscamos es desarrollar claves que permitan comprender dicha articulación.

\section{Trazados discursivos}

La cárcel pública de Valparaíso había comenzado a construirse desde 1846, en varias etapas sucesivas (Chapanoff 2001: 65-72). Dando fin a sus funciones en abril de 1999, la infraestructura planteaba problemas que se remontaban hacia muy atrás, debido al resguardo "patrimonial" que recaía en algunas de sus instalaciones- particularmente un antiguo polvorín español- y su posición urbana estratégica. Perteneciente a la Municipalidad de Valparaíso hasta 1998, la cárcel es vendida por la Alcaldía al Ministerio de Bienes Nacionales y, ya entre los años 2000 y 2002, la Secretaría Regional Ministerial de Bienes Nacionales desarrolla el programa "Cárcel, un cerro para la cultura". Orientada a rehabilitar el recinto como un espacio cultural abierto a la ciudadanía, esta iniciativa moviliza a artistas, colectivos culturales y organizaciones sociales locales en un proceso progresivo de ocupación, restauración y animación del lugar.

En octubre del año 2007, el alcalde demócrata-cristiano Aldo Cornejo presenta el "proyecto Niemeyer", consistente en un boceto de centro cultural pensado para ser construido sobre los terrenos del antiguo centro penitenciario, regalado por el arquitecto brasileño Óscar Niemeyer a la ciudad de Valparaíso. El estilo futurista, disonante con la impronta de la ciudad, así como la inexistencia de una consulta ciudadana previa, fueron denunciados desde un principio por los ocupantes del lugar y por diversas agrupaciones ciudadanas. Conjugado a otros factores de orden más técnico relativos a la normativa urbana, esto conduciría al abandono del proyecto en noviembre de 2008. Sólo en ese momento, el tema del destino de la Ex -cárcel será incorporado explícitamente al ámbito de competencia de las políticas culturales, y el CNCA asumirá un rol de mayor peso en la definición de los usos del lugar. Al año siguiente se abrirá un concurso para la propuesta de proyectos de arquitectura orientados a la construcción de un centro cultural llamado "Parque cultural Valparaíso", que entrará en funcionamiento a partir de 2011. Luego de una serie de tensiones sobre los espacios a ocupar 
en el intertanto de la construcción de este nuevo proyecto, y mediando un proceso de negociación que se vio además atravesado por el cambio de gobierno ${ }^{11}$, los artistas se instalan en el anfiteatro Manuel Guerrero (al que nombran alternativamente Parque cultural "La Laguna") en el Cerro Barón de Valparaíso.

Retomamos entonces nuestra pregunta inicial: de qué modo el proceso experimentado en Chile por este proyecto puede inscribirse en las políticas culturales de la Concertación? Podemos considerarlo en sintonía con el modelo económico neoliberal vigente? Esbozaremos tres entradas para dilucidar estas interrogantes.

\section{a. El ímpetu fundacional: partir de cero}

En su libro testimonial sobre la cultura en el gobierno de Ricardo Lagos, el asesor presidencial Agustín Squella señalaba que "el paso dado en materia de institucionalidad cultural tuvo un carácter fundacional" (Squella 2005: 133), refiriéndose a la creación del CNCA y al modo en que se integraron a esta entidad algunos los organismos preexistentes ${ }^{12}$. La afirmación parece lógica, en la medida que todo el aparataje cultural institucional del país debía reinventarse luego de la debacle de la dictadura. Más allá de eso, es interesante tomar esta idea como punto de referencia para leer otras operaciones que emergieron a propósito del proyecto Niemeyer, y que parecen asumir una retórica fundacional. En efecto, la manera en que el futuro centro cultural era presentado por sus promotores, esgrimiéndose la imagen de "partir de cero", omitía implícitamente la vigencia de prácticas culturales autogestionadas, ya durante siete años en ese entonces, en el antiguo penal.

Así, en una carta dirigida a la Gerente de Gestión del proyecto Niemeyer, las organizaciones respondían a la invitación a "crear" un centro cultural en el recinto:

nos resulta un tanto absurdo que se pueda crear algo que ya es, como el Parque Cultural Ex Cárcel, de siete años de emblemática historia. Este proyecto se podrá perfeccionar, rehabilitar, enriquecer o transformar, pero no crear. Tenga presente que si no es por el movimiento ciudadano que por siete años ha mantenido vivo el proyecto Parque cultural, hace tiempo ya que

\footnotetext{
${ }^{11}$ En marzo de 2010 concluye el mandato de Michelle Bachelet, socialista -cerrándose con esto dos décadas de gobiernos de la Concertación- y asume la presidencia el empresario Sebastián Piñera, representante de la derecha liberal chilena.

${ }^{12}$ Específicamente, la División de Cultura del Ministerio de Educación y el Departamento de Cultura del Ministerio Secretaría General de Gobierno.
} 
otros desarrollos muy distintos a los actuales se habrían impuesto. (Carta de organizaciones involucradas en la Ex Cárcel a Xochitl Poblete Rojas, Valparaíso, 16/10/2007) ${ }^{13}$

La negación discursiva que se puede entrever en esta convocación a "crear" algo que ya ha sido creado y se encuentra en funcionamiento, tiene como correlato la negación simbólica de la historia contenida en la Ex -cárcel como sitio de memoria colectiva. El proyecto arquitectónico operaría entonces no sólo como piedra inaugural, sino también como artífice de un doble olvido. Por una parte, la evacuación de una memoria ominosa propia del carácter carcelario del lugar, que desde una perspectiva oficial ciertamente comportaba una desvalorización del espacio urbano. Por otra, la omisión de la gestión colectiva por parte de diversas organizaciones y actores locales y su sustitución por el megaproyecto propuesto.

Según advierte Olivi, "en este período el recinto de la ex cárcel sufre numerosos incendios que perjudican seriamente la infraestructura. Las organizaciones sociales denuncian la utilización por parte de la administración pública de estos atentados incendiarios para argumentar la inseguridad del recinto y justificar el cierre del parque" (Olivi 2010: 332). En efecto, los numerosos y repetidos incendios que se arrastraban ya desde el año 2007, y cuyo origen nunca pudo ser aclarado ${ }^{14}$, habían devastado instalaciones en uso y materiales de trabajo, además de un pequeño museo levantado por un grupo de ocupantes, que registraba la historia del antiguo penal, resguardando documentos, objetos y mobiliario. Según se apuntaba en una nota de prensa de noviembre de 2007, retomando las declaraciones del Seremi de bienes Nacionales de la época, los incendios confirmarían la necesidad de dar un giro en los usos y habilitación del lugar:

\footnotetext{
${ }^{13}$ Para profundizar sobre las representaciones de las audiencias potenciales del nuevo centro que constituiría el proyecto de Niemeyer en Valparaíso, es interesante revisar el estudio "Infraestructura y propuesta de modelo de gestión cultural para Centro cultural de Valparaíso", encargado por la Unidad de Infraestructura y Gestión del CNCA en 2008, y realizado por un equipo multidisciplinario bajo la dirección de Javier Ibacache. Considerando distintos grupos de audiencias según segmento socioeconómico, los autores concluyen que, en torno al proyecto de Niemeyer, "la evaluación es ambigua. Por un lado la ciudadanía considera que se trata de un proyecto vanguardista, que es "bonito" y genera una imagen de futurismo. Pero al mismo tiempo, no se entiende cómo podrá dialogar con el entorno social. Las audiencias no observan que exista continuidad entre la mega construcción y la sencillez del cerro Cárcel. Dado que no lo han visto en los medios, las audiencias no dimensionan cómo es que el carácter innovador del proyecto de Oscar Niemeyer dialogará con el valor patrimonial que debe resguardar. La misma interrogante apunta a que finalmente se de lugar a un espacio de élite y que sea muy oneroso para los segmentos más bajos de la sociedad. Estas dudas distancian a la ciudadanía de la iniciativa" (Ibacache et al. 2008: 14-15).

${ }^{14}$ Así se señalaba en una nota de prensa: "Siete incendios en un año y medio ; intencionales, según Bomberos. Robos y desalojo con carabineros. Y un megaproyecto arquitectónico proyectado por el arquitecto brasileño Óscar Niemeyer, firmando la pena de muerte para el viejo penal”. La Nación, 17/08/2008.
} 
(el Seremi) dijo que será necesario dotar de un nuevo ordenamiento administrativo a la cárcel producto de la ocurrencia durante los últimos meses de otros siniestros y amagos de incendios generados en el lugar, lo que ha dejado de manifiesto la urgencia de generar a la brevedad un destino definitivo a un espacio subutilizado y en malas condiciones. (La Estrella de Valparaíso, 20/11/2007)

La política implícita de "hacer tabla rasa", que denuncian las organizaciones, pero que puede claramente entreverse en las declaraciones de autoridades, parece coherente con las propias afirmaciones de Jair Valera, arquitecto asesor de Niemeyer. Al referirse a las dificultades encontradas para implementar el proyecto en Chile, apuntaba: "no sé qué aconteció. La autoridad chilena llegó (primero) a la conclusión de que la (ex) cárcel no era tan importante y que podía ser demolida, y ahora cambiaron de pensamiento" (El Mercurio de Valparaíso, $8 / 11 / 2008)$.

Los siniestros serían el precedente del desalojo de los ocupantes de la Ex - cárcel en marzo de 2008 por orden del Gobierno Regional (GORE). El desalojo fue calificado posteriormente como un "error" de parte del GORE y la Corte de Apelaciones de Valparaíso acogió un recurso de protección que permitió el reingreso de los artistas y agrupaciones al recinto.

Más allá de una cronología de los hechos, los acontecimientos que aparecen más frecuentemente en la prensa de estos meses parecen emparentarse, conformando un correlato de este afán fundacional. Demolición, incendio, desmantelamiento y desalojo sugieren así un afán de supresión de lo existente para re-comenzar desde cero, reenviándonos a la épica atribuida a las titánicas empresas de Niemeyer, quien, tal como advertía una nota de prensa a propósito de Brasilia, “construyó en 42 meses, en un páramo desolado, el sueño brasileño del siglo XXI" (La Nación, 13/12/2007).

Podía acaso la Ex - cárcel reconducirse a un espacio baldío de tales características? O más allá, el imaginario de este deseado espacio de ebullición creativa fundado ex - nihilo sobre un terreno limpio y desierto, no podría ser una metáfora del "american dream", de éxito individual explosivo a partir de la nada? Según Díaz (2013), "el espacio discursivo en que la arquitectura despliega sus narrativas es también suelo fértil para reemplazar o borrar un pasado incómodo, cubriéndolo con nuevas historias". De qué nueva historia o relato se trata aquí? Podríamos partir advirtiendo que si la puesta en marcha autogestionada en el Parque Ex - cárcel aparecía como una construcción eminentemente colectiva, la retórica pro-Niemeyer 
era un discurso que ponía de relieve un emprendimiento individual, una figura solitaria e inspirada, clásica imagen del genio creador.

\section{b. La marca Niemeyer: un artista autónomo}

Ya hace una par de décadas, Henri Lefevbre planteaba la pregunta: "cómo la hegemonía dejaría de lado el espacio?” (Lefevbre 1986: 18). Quizás resulte curioso que intentemos esclarecer la figura de Oscar Niemeyer y su proyecto a partir de allí, siendo el arquitecto un reconocido hombre de izquierda, anticapitalista de vieja escuela. No obstante, es necesario esclarecer aunque sea fragmentariamente qué representa esta "impronta mundial de la marca Niemeyer" (El Mercurio de Valparaíso, 7/11/2008) que circuló en los discursos públicos durante los meses en que fue promovido el controversial proyecto.

Esta noción de "marca" resulta particularmente sugerente al repensarla desde un ángulo más teórico. En la medida que se inscribe en procesos de apropiación espacial simbólica "la marca es la expresión de un cierto poder, al menos aquél de marcar más o menos duraderamente el espacio, y de afirmarse en él" (Veschambre 2008: 11). A diferencia de las "huellas" que remiten al pasado, a partir de procesos anónimos y no intencionales, la marca y el proceso de establecerla- en un espacio construido, remite a un actor y hace referencia a un presente: "La marca funciona como firma intencional: es pensada y producida para hacer visible una persona, un grupo, una institución, para constituir el soporte de una identificación (individual o más generalmente colectiva), y para representar el atributo del actor o del grupo en cuestión" (Veschambre: 11). Desde aquí, podría plantearse que si la cárcel constituía desde larga data una huella de distintas capas del pasado, sobre la cual se inscribe la marca del "Parque cultural" a partir del comienzo de la década, el proyecto de Niemeyer- y el posicionamiento de su figura como punta de lanza de dicho proyecto- constituye una segunda marca que vendría a imponerse a la anterior. Pero entonces habría que preguntarse: desde dónde es construida esta marca? Qué valores moviliza y qué articulaciones establece con otros valores vigentes en la sociedad chilena esos años, particularmente en lo que refiere a las políticas culturales?

En una entrevista publicada en Francia en 2007, el arquitecto brasileño daba cuenta de ciertas premisas creativas de su trabajo: "Según yo, el arquitecto debe hacer lo que le gusta, y 
no lo que los otros quisieran que él haga" (Niemeyer 2007: 39), "el acto de creación, a mi parecer, no admite reglas y está enteramente hecho de sorpresa e imaginación” (Niemeyer 2007: 44).

El regalo del proyecto a Valparaíso, argüía como motivo la amistad de Niemeyer con Pablo Neruda y Salvador Allende: el poeta, el presidente, y el arquitecto brasilero compartían, en efecto, haber recibido el Premio Lenin de la paz entre los pueblos, por parte de la Unión Soviética, lo que los incorporaba a un imaginario de izquierda compartido que, particularmente en el caso de Niemeyer, se articulaba directamente a las ideas desarrollistas de mediados del siglo $\mathrm{XX}^{15}$. Ciertamente el "recurso a Niemeyer"- si retomamos los planteamientos de Yúdice (2002) señalados en un inicio- podía así reportar créditos a la coalición de gobierno, que diagnosticaba ya desde sus primeros años, que el país estaba "en deuda con la cultura", proponiendo generar "estímulos, regulaciones y controles que eviten los abusos y disminuyan las desigualdades de acceso a la creación y el disfrute cultural" (Foxley Rioseco 1999: 35). La implantación del proyecto del arquitecto visibilizaría así las avanzadas del gobierno para el establecimiento de condiciones para un modelo cultural democrático nacional.

Si por un lado la marca Niemeyer nos remite a un imaginario idóneo para ser capitalizado como recurso político, habría que detenerse también en los alcances de las consideraciones artísticas hacia su obra.

Vemos así que reaparece, en diversos discursos circulantes en torno al trabajo del arquitecto, un énfasis en la autonomía del arte, entendiendo sus proyectos como obras "de autor" que exigirían "ser percibida(s) según una intención puramente estética, es decir, en su forma más que en su función" (Bourdieu 1979: 29).

Así, en una nota de prensa el periodista pregunta a Jair Valera, asesor del arquitecto: “¿Es la arquitectura de Niemeyer forma y sólo forma?" a lo que responde "No, es tecnología engarzada con la naturaleza (...) Nos gusta calcular las sensuales formas de Óscar y convertirlas en edificios" (La Nación, 16/12/2007). En otra oportunidad, el mismo asesor

\footnotetext{
${ }^{15}$ En una aproximación al trabajo de Niemeyer, se señala: "Los eternos escépticos no entendían que Brasilia iba a dar un impulso al desarrollo de la 'hinterland', como en seguida lo constatamos: construcción de rutas, de aldeas, de escuelas, consultorios, multiplicación de líneas de buses interurbanos, valorización de las tierras vírgenes, etc." (Niemeyer y Bailby 1993: 87). Adrián Gorelik, en tanto, se refiere a Brasilia como "la ciudad producto por excelencia de una representación cultural de la modernidad latinoamericana” (Gorelik 2004).
} 
declara en relación al proyecto: "La gente tiene que entender que puede decir cómo lo quiere, pero la arquitectura es una forma, que la hace el arquitecto que está preparado para ello" (El Mercurio de Valparaíso, 28/11/2007)

A esta cualidad formal y autónoma, pareciera atribuírsele una suerte de poder consagratorio que no se limita al sitio de la prisión: Se trataría de un "sello inconfundible" (El Mercurio de Valparaíso, 25/11/2007) que irradiaría a la ciudad completa, confiriéndole una impronta artística capaz de legitimarla. De este modo, otro artículo de la época, evaluaba los alcances del proyecto:

Niemeyer es un arquitecto de renombre, y su obra sería una de magnitud y trascendencia. Las obras de trascendencia detonan un impacto sumamente positivo en ciudades en proceso de regeneración, pueden llegar a constituirse en una imagen reconocible a nivel internacional (como es el caso de museo Guggenheim en Bilbao, por ejemplo). La obra de Niemeyer es probable genere plusvalías al entorno de la ex cárcel. (Canales, 2007)

Como todo potencial "consagratorio", este debía operar en base a una creencia que, en tanto tal, requería ser producida ${ }^{16}$, instalándose en el discurso público. Aparecen así ciertas tácticas oficiales de difusión y de promoción de la obra del arquitecto como arte consagrado, y asimismo como arte de fuerte potencial consagratorio respecto a sus espacios de intervención. Llama la atención, en este marco, que sólo algunos meses después de los incendios y el desalojo antes mencionados, se hayan realizado dos exposiciones retrospectivas dedicadas al arquitecto brasileño, simultáneamente en el Museo Nacional de Bellas Artes (MNBA) y en la Fundación Itaú, con el título "La poética de la forma". El paso por la institución-museo reafirma la cualidad artística de la figura de Niemeyer, intentando expandir su valoración local. Pero no sólo eso: la cronología propuesta de sus trabajos, en un claro gesto performático, exhibía el irrealizado proyecto para la Ex - cárcel como el último eslabón de la secuencia, como una obra acabada más. Respecto a esto, un artículo de prensa de la época indicaba: "aunque aún no se ha puesto ninguna primera piedra, el diagrama de aquella construcción se encuentra terminado y es parte importante de la muestra ubicada en el MNBA" (La Tercera, 19/06/2008).

\footnotetext{
${ }^{16}$ Para Bourdieu "el capital simbólico asegura formas de dominación que implican la dependencia de aquellos que permite dominar. No existe, en efecto, más que en y por la estima, el reconocimiento, la creencia, el crédito, la confianza en otros, y sólo puede perpetuarse por el tiempo que logre obtener la creencia en su existencia" (Bourdieu 1997: 200).
} 
Es importante aquí detenernos en las resonancias que esto plantea con las lógicas de las políticas culturales de la época. Como lectura preliminar, el proyecto parece guiarse por premisas comunes a ciertas premisas impulsadas por el organismo formal de financiamiento artístico-cultural, el Fondart, creado en 1992 por el en ese momento Ministro de Educación, Ricardo Lagos. Ya antes hemos hecho referencia a la primacía dada a la idea de autonomía en la configuración de las políticas culturales a partir de 1990: Esta aparece como una categoría de oposición a las condiciones de autoritarismo y represión que marcaron el campo cultural durante dictadura, pero implicará también que el rol institucional ante la cultura, ya en democracia, sea definido en los discursos en términos eminentemente formales, condenándose así toda idea de "dirigismo" en este plano.

Lo mismo queda a la vista luego de una serie de polémicas que entrecruzaron arte y política a partir de obras financiadas por el Fondart, en que el organismo no sólo reaccionó reivindicando la recientemente rehabilitada libertad de expresión, sino además reafirmando la cualidad neutral y técnica de sus procedimientos. Tal como se señalaba en ese momento, uno de los elementos esenciales que aseguraban dicha condición neutral, era la evaluación en base a la excelencia, ejecutada por especialistas. Lo que desde cierto ángulo podría ser visto como una "ideología Fondart" (Carvajal y van Diest 2009), converge tanto con la manera en que, ya lo veíamos más arriba, el propio Niemeyer tematiza su arquitectura- una expresión directa de su gusto y sentimientos- como con el modo en que fue promocionado localmente, poniendo énfasis en la experticia individual ${ }^{17}$.

En esta misma línea, y retomando los antes mencionados planteamientos de Jair Varelaasesor del arquitecto y promotor del proyecto en Chile- el propio carácter formal, neutral y técnico que se atribuye a las políticas culturales en democracia parece menos claro. Desde los discursos públicos, el proyecto Niemeyer se convierte así en portador de una distinción entre prácticas culturales legítimas e ilegítimas, y en canalizador de una serie de aspiraciones para la ciudad - y, en términos más amplios, para el país-.

El gran arte no es democrático ni opera por consenso. Tómelo o déjelo. Valparaíso haría historia si le otorga libertad total a Niemeyer. Quedaríamos en las leyendas del siglo XXI. A su vez, el

\footnotetext{
${ }^{17}$ Ello si bien, a diferencia de las lógicas de Fondart, su selección no siguió la lógica del "concurso" sino la del "don": don que no puede rechazarse, por un lado, y que, por otro, nunca es realmente gratuito (Véase Douglas 2004)
} 
fracaso de esta iniciativa sería la confirmación de que aquí hay una maldición histórica que nos condena a la mediocridad, a la incultura y a la falta de civilización. (El Mercurio de Valparaíso, $09 / 12 / 2007)$

Así se pronunciaba un académico de la Universidad Técnica Federico Santa María, de Valparaíso, sobre el obsequio de Niemeyer a la ciudad, encontrándose aun en ciernes las querellas que se suscitarían al año siguiente. Como vemos, las referencias a una cualidad artística consagrada, la autonomía del arte respecto a lo político-social, y las proyecciones globales, quedan aquí estrechamente articuladas. Pero las formulaciones que propone este fragmento van más allá, en la medida que se establece un claro vínculo entre posicionamiento internacional - alineado a la inscripción histórica que se imaginaba alcanzaría Valparaíso - y la "legitimidad" o "ilegitimidad" cultural. Es así, que la propia ciudad es representada como fuente primera de la ilegitimidad, la insignificancia o, en otras palabras, de la incultura y la mediocridad.

\section{c. Posicionamientos globales y megaeventos}

Hemos dicho que la promoción oficial del proyecto Niemeyer para la ex cárcel establece una relación conflictual con la memoria urbana en torno al espacio carcelario, con el parque cultural sostenido colectivamente por distintos ocupantes locales, a la vez que la "marca" promocionada del arquitecto plantea paralelismos con una valoración de la autonomía, de la excelencia, y de la individualidad, latente en el discurso de las políticas culturales en Chile. Vinculado a la imagen consagratoria del artista, construida y reforzada a través de diversas instancias, esto nos redirige a un imaginario de "ciudades" que traspasa el contexto específico de Valparaíso. Resulta importante entonces indagar cómo se articula lo local y lo global en torno a este proyecto.

Para ello, debiéramos remitirnos a la génesis del proceso en que éste se inscribe, en que nos encontramos con una situación de interés para nuestro análisis. Se trata del Segundo Fórum internacional de las culturas, realizado en 2007 en la ciudad mexicana de Monterrey, bajo el auspicio de la Unesco. La primera versión de este evento había sido realizada tres años antes en Barcelona. Este megaevento apuntaba desde su concepción a vender la imagen de la ciudad, bajo el financiamiento "de fondos públicos pero gestionado bajo el modelo y a favor 
del capital privado" (Delgado 2004: 30), bajo la misma lógica del antes aludido "modelo Barcelona". Se trataba de un macro evento político y económico mediado por todas las herramientas de la propaganda institucional, en un encuadre apropiadamente cultural.

Es en este contexto y con ocasión del segundo Fórum, en Monterrey, que se establecerían ciertos compromisos políticos determinantes para el impulso que a nivel local se le daría a este evento: "Valparaíso es una ciudad destinada a convertirse en una urbe internacional por el prestigio de su calidad académica y por su industria cultural" (El Mercurio de Valparaíso, 09/12/2007), afirmaba entonces el Gobernador del Estado de Nuevo León (del que Monterrey es capital) al tiempo que el alcalde Aldo Cornejo se comprometía a que ésta fuera la sede del Fórum para el año 2010. Ya desde entonces, el proyecto Niemeyer se esbozaba en el imaginario político como la sede soñada, inmaculada e hipermoderna del acontecimiento. En ese mismo sentido, un artículo precisaba en torno a la propuesta de Niemeyer: "el proyecto ya cuenta con 5.767 millones de financiamiento y fue el resultado de una serie de gestiones lideradas por el alcalde Cornejo para dotar a Valparaíso de una obra emblemática para la celebración del Bicentenario en Chile" (Magnasco, 2008) ${ }^{18}$.

Nos encontramos de este modo ante la confluencia significativa de dos fenómenos: los discursos celebratorios del Bicentenario, por un lado, y por otro, el Forum de las culturas, ambos previstos para 2010, coincidiendo con el año proyectado para la inauguración del centro cultural. Notemos aquí la superposición de dos narrativas: en primer lugar, Niemeyer constituye el broche de oro de un evento histórico-temporal que confrontaría al país con su propia auto-representación como país desarrollado y capaz de enormes logros infraestructurales en el horizonte de sus 200 años. En segundo lugar, se despliega una narrativa espacial, en que el mismo proyecto cristaliza como sede de lo global, localizando tan sólo por un momento la complejidad de las redes transnacionales ${ }^{19}$.

\footnotetext{
${ }^{18}$ Por otra parte, el gesto oficial de "celebrar inaugurando", es decir, de marcar hitos históricos con hitos infraestructurales, no representa aquí una novedad: Ya el primer centenario había sido celebrado con la construcción de edificios que se incorporan ejemplarmente al imaginario republicano: el Museo Nacional de Bellas Artes y la Biblioteca Nacional.

${ }^{19} \mathrm{Si}$ bien aquí no ahondamos en este tema, es interesante constatar el tajante contraste que esto involucra respecto a los imaginarios urbanos de los propios habitantes respecto a la categoría "patrimonial" de Valparaíso, en que las representaciones de la ciudad como "ruina"- y su contraparte directa: la necesidad de "recuperación"adquieren un lugar protagónico (Véase Guajardo 2003).
} 
La importancia otorgada al proyecto trascendía, en efecto, su vigencia real en la agenda pública: ya en 2006, el Secretario ejecutivo de la Comisión de gestión e infraestructura cultural durante el gobierno de Lagos, Arturo Navarro, estimaba que "la vieja cárcel debiera llegar a ser el símbolo de la nueva escala global que ha adquirido Valparaíso luego de ser declarado Patrimonio de la Humanidad, que permita el desarrollo de las artes en una dimensión de excelencia y calidad en el ámbito nacional e internacional" (Navarro Ceardi 2006: 105)

La relevancia del proyecto tendrá entonces que ver con su capacidad de representar localmente lo global, a la vez que de canalizar un imaginario productivo de una visión de futuro (Baczko 1984: 35), constituyendo al mismo tiempo una marca de legitimidad que sacaría a la ciudad de su supuesto anonimato, otorgándole un imaginado reconocimiento internacional.

El fenómeno plantea de este modo la interrogante sobre cómo transitoriedad y permanencia son negociadas en el ámbito del manejo político-cultural, en que "eventos" e "infraestructuras" parecieran a primera vista encontrarse en registros opuestos- lo pasajero, lo permanente- a la vez que introduce la pregunta por cómo lo local y lo global se articulan en el desarrollo de controversias inscritas en espacios no metropolitanos. Los megaeventos se desplegarían así como herramienta de una virtual reactivación económica y del imaginado posicionamiento de las ciudades en una esfera competitiva internacional.

Se trataría así de la imaginación oficial de aquella ciudad deseada que contrasta de manera aguda con la ciudad vigente: una ciudad exitosa y rentable, favorecida por las leyes del mercado y el consecuente desarrollo del turismo y los servicios, a partir de ciertas marcas prestigiosas que- desde el recurso a un renombre artístico individual- la legitiman y posicionan en una vitrina internacional. Es difícil entonces distinguir si el proyecto Niemeyer se articula a las políticas culturales de gobierno, a la ideología vigente del sistema económico neoliberal, o más bien, a lo que podría considerarse una intersección entre ambas. La primacía de lo individual por sobre lo colectivo- con su consecuente valoración de la "excelencia"- el énfasis en una racionalidad técnica experta y en los marcos formales, la predominancia del mercado como criterio regulatorio de los flujos entre lo local y lo global, en que la imagen de la ciudad constituiría un valor agregado (del mismo modo que los documentos oficiales antes 
revisados conciben la cultura respecto a la economía) parecen atravesar el proceso vivido por el proyecto del arquitecto brasileño en Valparaíso. Como ya decíamos en un comienzo, la imaginación oficial es también aquello que se desea, y que en este trabajo hemos vinculado a un ejercicio del poder desde lo institucional. En la medida que nos referimos a este deseo, los discursos de la neutralidad, los marcos formales y el "emprendimiento individual" albergan ciertamente un trasfondo sustantivo del tipo de sociedad que se busca construir.

\section{Consideraciones finales}

Hemos analizado de qué modo el proyecto donado por el arquitecto brasileño Oscar Niemeyer para ser levantado en los terrenos de la Ex cárcel de Valparaíso moviliza un paradigma implícito en las políticas culturales impulsadas por los gobiernos de la Concertación.

Partimos de la noción de imaginación para considerar desde allí que el ejercicio de las instituciones no podrá calificarse meramente en términos formales- aun cuando, como hemos observado, este sea el discurso que las instituciones detenten sobre su propio operar-. Entendiendo lo imaginario como capacidad de institución de lo "nuevo", y a un ejercicio del poder, recurrimos a los discursos de prensa para explorar tal articulación.

Proponemos así tres posibles entradas: En primer lugar los discursos que promocionan el proyecto de Niemeyer ponen de relieve la idea de "partir de cero". Tanto la memoria urbana de la cual que la cárcel es portadora, como el quehacer autogestionado que diversos colectivos, actores locales y artistas desarrollaban desde comienzos del 2000, son así omitidos bajo una lógica de tabla rasa. Esta operación es coherente con el modo en que el propio trabajo de Oscar Niemeyer es tematizado (creador de ciudades ex -nihilo), planteando también paralelismos con el discurso fundacional de las políticas culturales concertacionistas.

En segundo lugar, el proyecto del arquitecto es promocionado a partir de la valorización de una "marca" basada en su figura artística. Esta marca funciona como recurso político, pero también se corresponde con los principios declarados de las políticas culturales, en tanto la categoría de "autonomía" se destaca de manera protagónica. Entendida aquí como una primacía de lo formal y una comprensión de su trabajo como "obra de arte", se imagina que la marca Niemeyer revalorizaría la ciudad proyectándola a una esfera internacional. La figura 
individual del artista funciona entonces como componente de un capital simbólico que se espera recaiga sobre un Valparaíso juzgado como ilegítimo.

Finalmente, el proyecto de Niemeyer es tematizado por los discursos públicos a la luz de eventos de amplio alcance simbólico, que lo sobrepasan: las celebraciones del Bicentenario, el Fórum de las Culturas, la investidura de Valparaíso como Patrimonio de la Humanidad por parte de la Unesco. Desde esa perspectiva, el proyecto no sólo se inscribe en el cruce de lo local y lo global, sino que constituye también una excusa para imaginar el futuro. Hemos leído esto como un correlato del modelo económico de libre mercado, en que - desde los anhelos y discursos oficiales - la imagen de un Chile plenamente globalizado se vuelve dominante.

Las aproximaciones que aquí desarrollamos dejan abierta la necesidad de articular estos análisis a una perspectiva que problematice los significados y representaciones atribuidos al lugar por los propios actores y artistas ocupantes, así como por los habitantes de la ciudad. 


\section{Bibliografía}

Ahearne, Jeremy. 2009. "Cultural policy explicit and implicit: a distinction and some uses". International Journal of cultural policies, 15 (2): 141-153.

Aravena, Pablo; Sobarzo, Mario. 2009. Valparaíso: Patrimonio, mercado y gobierno. Concepción: Escaparate Ediciones.

Baczko, Bronislaw. 1984. Les imaginaires sociaux. Mémoires et espoirs collectives. Paris: Payot

Bourdieu, Pierre. 2003. Creencia artística y bienes simbólicos. Córdoba y Buenos Aires: Aurelia Rivera Editorial.

1997. Méditations Pascaliennes. Paris: Editions du Seuil.

1979. La distinction. Critique sociale du judgement. Paris: Les Éditions du Minuit.

Canales, Macarena. 2007. "El proyecto de Niemeyer para la ex cárcel de Valparaíso". En línea, disponible en: http://www.plataformaurbana.cl/archive/2007/10/08/el-proyecto-deniemeyer-para- la-ex-carcel-de-valparaiso/ (visitado el 5 de octubre de 2013).

Candau, Joel. 1996. Anthropologie de la mémoire. Vendôme: Presses Universitaires de France.Cárcamo-Huechante, Luis. 2007. Tramas del mercado: Imaginación económica, cultura pública y literatura en el Chile de fines del siglo veinte. Santiago de Chile: Editorial Cuarto Propio.Carvajal, Fernanda; van Diest, Camila. 2009. Nomadismos y ensamblajes. Compañias teatrales en Chile (1990-2008). Santiago de Chile: Editorial Cuarto Propio. Castoriadis, Cornelius. 1999. L'institution imaginaire de la société. Paris: Éditions du Seuil. Chapanoff, Miguel. 2001. Espacios de prisión en Valparaíso 1692- 1940. Del mundo correccional a la significación del lugar. Chile: Ministerio de Bienes Nacionales.

Consejo Nacional de la Cultura y las Artes. 2005. Chile quiere más cultura. Definiciones de política cultural 2005-2010, Santiago de Chile.

Delgado, Manuel. 2004. La otra cara del forum de las culturas. Barcelona: Ediciones Bellaterra.

Díaz, Francisco. 2013. "Los arquitectos y la falta de memoria". Bifurcaciones 7. En línea, disponible en: http://www.bifurcaciones.cl/2013/07/los-arquitectos-y-la-falta-de-memoria/ (visitado el 4 de enero de 2014).

Douglas, Mary. 2004. "Il n'y a pas de don gratuit". Comment pensent les institutions. Paris: Éditions La Découverte.

Drake, Paul; Jaksic, Iván. (Eds.). 2002. El modelo chileno. Democracia y desarrollo en los noventa. Santiago de Chile: Lom Ediciones. 
Fazio Rigazzi, Hugo. 2006. Lagos, el Presidente "progresista” de la Concertación. Santiago de Chile: Lom Ediciones

Foxley Rioseco, Ana María.1999. "Señales para un cambio". Chile 1990-2000. Una década de desarrollo cultural. Edición especial Revista Cultura 25, Santiago de Chile, Secretaría de Comunicación y Cultura: 32-35.

Garretón, Manuel Antonio. 1993. La faz sumergida del iceberg. Estudios sobre la transformación cultural. Santiago de Chile: Lom - Cesoc.

González Troncoso, Félix. 2010. Reconstrucción del espacio social-urbano: La disputa por el modelo de gestión de la ciudad de Valparaíso (Memoria de Grado inédita para optar al Grado de Licenciado en Sociología y Titulo Profesional de Sociólogo). Universidad de Valparaíso, Viña del Mar, Chile.

Gorelik, Adrián. 2004. "Imaginarios urbanos e imaginación urbana. Para un recorrido por los lugares comunes de los estudios culturales urbanos". Bifurcaciones 1. En línea, disponible en: http://www.bifurcaciones.cl/001/bifurcaciones_001_AGorelik.pdf (visitado el 15 de noviembre de 2013).

Guajardo, Gabriel. 2003. Caracterización de la opinión y representación ciudadana y de grupos sociales sobre la imagen, expectativas o alternativas de uso del patrimonio cultural de la ciudad de Valparaíso. Santiago: FLACSO.

Harvey, David. 2002. "The art of rent. Globalization, monopoly and the commodification of culture". Socialist Register 38: 93-110.

Jiménez Yáñez, César y Muñoz Cerda, Jorge. 2011. "El rol del Estado y la concentración mediática en Chile". Diálogos de la comunicación 82. En línea, disponible en: http://www.dialogosfelafacs.net/el-rol-del-estado-y-la-concentracion-mediatica-en-chile/ (visitado el 10 de junio de 2010)

2009. "Políticas públicas y el rol del Estado en los medios de comunicación en Chile". Enlaces: revista del CES Felipe II, 10. En línea, disponible en: http://www.cesfelipesegundo.com/revista/articulos2009/Cesar.pdf (visitado el 10 de junio de 2010).

Lagos, Ricardo. 2003. "Palabras del Presidente Ricardo Lagos en la ceremonia de firma del Proyecto de Ley que Crea el Consejo Nacional de Cultura". En línea, disponible en: www.culturachile.cl/documentos/palabras pdte.php (visitado el 15 de noviembre de 2013).

Lefevbre, Henri. 1986. La production de l'espace. Paris: Anthropos.

Legros, Patrick et al. 2006. Sociologie de l'imaginaire. Paris: Armand Colin. 
Magnasco, Mauricio. 2008. "Encuesta: Si o no al proyecto Niemeyer en Valparaíso". En línea, disponible en: http://www.plataformaurbana.cl/archive/2008/01/20/encuesta-si-o-noal-proyecto-de- niemeyer-en-valparaiso/ (visitado el 30 de noviembre de 2013)

Miller, Toby; Yúdice, George. 2004. Politica cultural. Barcelona: Gedisa.

Navarro, Arturo. 2006. Cultura, quién paga? Gestión, infraestructura y audiencias en el modelo chileno de desarrollo cultural. Santiago de Chile: Ril Editores.

Niemeyer, Oscar; Trasi, Nicoletta. 2007. Permanence et invention. Questions d'architecture. Entretien realisé et présenté par Nicoletta Trasi. Paris: Editions du Moniteur.

Niemeyer, O; Bailby, E. 1993. Niemeyer par lui même. L'architecte de Brasilia parle à Edouard Bailby. Paris : Éditions Balland.

Olivi, Alessandra. "Gente mala en tierra buena. Dinámicas conflictivas para la construcción de la ciudad: el caso de la ex cárcel de Valparaíso". 2010. Antropología de Iberoamérica: estudios socioculturales en Brasil, España, México y Portugal. Espina Barrio, Ángel; González de la Fuente, Íñigo (Eds.). Recife: Editorial Massangana-Fundação Joaquim Tabuco. 313-339.

Quéré, Louis. 1992. “L'espace public. De la théorie politique à la métathéorie sociologique". Quaderni 18: 75-92.

Rodríguez, Miguel. "Propaganda del sentimiento: Conmemoraciones y monumentos". 2001. España, Francia y América Latina. Políticas culturales, propagandas y relaciones internacionales, siglo XX. Delgado Escalonilla, Lorenzo et al. París, Budapest, Torino: L'Harmattan. 403-482.

Sepúlveda Ocampo, Rubén et al. 2009. "Bicentenario: oportunidad de repensar las políticas urbano - habitacionales en Chile”. Revista INVI 24 (67). En línea, disponible en http://www.scielo.cl/pdf/invi/v24n67/art02.pdf (visitado el 5 de diciembre de 2013).

Sironneau, Jean-Pierre. 1993. Figures de l'imaginaire religieux et dérive idéologique. Paris: L'Harmattan.

Squella, Augustín. 2005. El Jinete en la Lluvia. La cultura en el gobierno de Lagos. Santiago de Chile: Aguilar.

Stambuk, Patricia. 1999. "El desequilibrio informativo en Chile: discriminación de la noticia regional en la prensa nacional". Revista Latina de Comunicación Social 14. En línea, disponible en http://www.ull.es/publicaciones/latina/a1999c/133valpara.htm (visitado el 10 de junio de 2013)

Sunkel, Guillermo; Catalán, Carlos. “Comunicación y política en América Latina”. 1993.

Historia crítica 7: 81-91. En línea, en 
http://historiacritica.uniandes.edu.co/view.php/122/index.php?id=122 (visitado el 10 de junio de 2014).

van Dijk, Teun. 1996. "Opiniones e ideologías en la prensa”. Voces y culturas 10. En línea, disponible en

http://www.discursos.org/oldarticles/Opiniones\%20e \%20ideolog\%EDas $\% 20$ en $\% 201 \mathrm{la} \% 20$

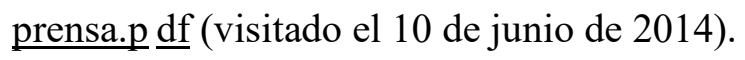

Vanni, Michel. "Imaginaire et invention sociale-historique: entre autonomie et hétéronomie". 2006. L'imaginaire selon Castoriadis.Thèmes et enjeux. Klimis, Sophie; Van Eynde, Laurent (Eds.) Bruxelles: Facultés universitaires Saint-Louis. 151- 166.

Veschambre, Vincent. 2008. Traces et mémoires urbaines. Enjeux sociaux de la patrimonialisation et de la démolition. Rennes: Presses Universitaires de Rennes.

Yúdice, George. 2002. El recurso de la cultura. Barcelona: Gedisa.

\section{Documentos de prensa}

"Extraño caso de incendio pasa al Consejo de Defensa del Estado". La Estrella de Valparaíso. 20/11/2007

"Para Niemeyer es un honor hacer una obra en Valparaíso". El Mercurio de Valparaíso. 25/11/2007.

“Misión Niemeyer fija plazos". El Mercurio de Valparaíso. 28/11/2007.

"Defensores del proyecto Niemeyer. Nuevo punto de referencia". El Mercurio de Valparaíso. 09/12/2007.

"Este será un gran desafío". El Mercurio de Valparaíso. 09/12/2007.

“Oscar, feliz centenario". La Nación. 13/12/2007.

"El arquitecto Niemeyer cumplió su centenario". La Nación. 16/12/2007.

“Las formas y el tiempo según Oscar Niemeyer”. La Tercera. 19/06/2008. En línea,

disponible en http://www.latercera.com/contenido/29_23341 9.shtml (visitado el 3 de enero de 2014).

“La Samba de la cárcel”. La Nación. 17/08/2008.

"Definitivo, proyecto Niemeyer para ex Cárcel de Valparaíso no va más". El Mercurio de Valparaíso. 7/11/2008.

"Niemeyer está triste y decepcionado por fracaso del proyecto Ex Cárcel". El Mercurio de Valparaíso. 8/11/2008. 


\section{Documentos}

Carta a Xochitl Poblete Rojas, Gerente de Gestión Proyecto ex Cárcel. Valparaíso. Documento no publicado. 16/10/2007. 
Anexo

Cuadro: Corpus de artículos de prensa, El Mercurio de Valparaíso y La Estrella de Valparaíso.

\begin{tabular}{|c|c|c|c|}
\hline & Título & Publicación & Fecha \\
\hline 1 & "Oscar Niemeyer tras ex cárcel" & $\begin{array}{l}\text { El Mercurio de } \\
\text { Valparaíso }\end{array}$ & 10 de mayo 2007 \\
\hline 2 & "Lista propuesta cultural" & $\begin{array}{l}\text { El Mercurio de } \\
\text { Valparaíso }\end{array}$ & 15 de mayo 2007 \\
\hline 3 & "Polémica por proyecto de la ex Cárcel" & $\begin{array}{l}\text { El Mercurio de } \\
\text { Valparaíso }\end{array}$ & 18 de mayo 2007 \\
\hline 4 & "Grupos culturales protestaron en defensa de la ex Cárcel" & La Estrella & 19 de mayo 2007 \\
\hline 5 & "Hay acuerdo por ex Cárcel" & $\begin{array}{l}\text { El Mercurio de } \\
\text { Valparaíso }\end{array}$ & 24 de mayo 2007 \\
\hline 6 & "Guerra por el futuro de Ex Cárcel" & La Estrella & 10 de octubre 2007 \\
\hline 7 & "El proyecto Niemeyer es sólo oportunismo político" & La Estrella & 10 de octubre 2007 \\
\hline 8 & "Ahora llueven los proyectos para la Ex cárcel de Valparaíso" & La Estrella & 19 de octubre 2007 \\
\hline 9 & "Quién es Oscar Niemeyer" & La Estrella & 20 de octubre 2007 \\
\hline 10 & $\begin{array}{l}\text { "Extraño caso de incendio pasa a Consejo de Defensa del } \\
\text { Estado" }\end{array}$ & La Estrella & $\begin{array}{l}20 \text { de noviembre } \\
2007\end{array}$ \\
\hline 11 & "Para Niemeyer es un honor hacer una obra en Chile" & $\begin{array}{l}\text { El Mercurio de } \\
\text { Valparaíso }\end{array}$ & $\begin{array}{l}25 \text { de noviembre } \\
2007\end{array}$ \\
\hline 12 & "Enojados por exclusión" & $\begin{array}{l}\text { El Mercurio de } \\
\text { Valparaíso }\end{array}$ & $\begin{array}{l}26 \text { de noviembre } \\
2007\end{array}$ \\
\hline 13 & "Misión Niemeyer con la lupa" & $\begin{array}{l}\text { El Mercurio de } \\
\text { Valparaíso }\end{array}$ & $\begin{array}{l}27 \text { de noviembre } \\
2007\end{array}$ \\
\hline 14 & "Misión Niemeyer fija plazos" & $\begin{array}{l}\text { El Mercurio de } \\
\text { Valparaíso }\end{array}$ & $\begin{array}{l}28 \text { de noviembre } \\
2007\end{array}$ \\
\hline 15 & "La 'Cárcel Niemeyer”" & $\begin{array}{l}\text { El Mercurio de } \\
\text { Valparaíso }\end{array}$ & $\begin{array}{l}04 \text { de diciembre de } \\
2007\end{array}$ \\
\hline
\end{tabular}




\begin{tabular}{|c|c|c|c|}
\hline 16 & $\begin{array}{l}\text { "Con colorida marcha protestaron por el futuro de la cárcel } \\
\text { porteña" }\end{array}$ & La Estrella & $\begin{array}{l}07 \text { de diciembre } \\
2007\end{array}$ \\
\hline 17 & $\begin{array}{l}\text { "Organizaciones se sientan a la mesa para discutir futuro de la } \\
\text { ex Cárcel" }\end{array}$ & La Estrella & $\begin{array}{l}08 \text { de diciembre } \\
2007\end{array}$ \\
\hline 18 & $\begin{array}{l}\text { "Defensores del proyecto Niemeyer. Nuevo punto de } \\
\text { referencia" }\end{array}$ & $\begin{array}{l}\text { El Mercurio de } \\
\text { Valparaíso }\end{array}$ & 9 de diciembre 2007 \\
\hline 19 & "Este será un gran desafío". & $\begin{array}{l}\text { El Mercurio de } \\
\text { Valparaíso }\end{array}$ & $\begin{array}{l}09 \text { de diciembre } \\
2007\end{array}$ \\
\hline 20 & "Por séptima vez queman la ex Cárcel de Valparaíso" & La Estrella & 06 de marzo 2008 \\
\hline 21 & "Determinan cierre de centro cultural ex Cárcel" & La Estrella & 22 de marzo 2008 \\
\hline 22 & "Crece molestia por desalojo de ex Cárcel" & $\begin{array}{l}\text { El Mercurio de } \\
\text { Valparaíso }\end{array}$ & 25 de marzo 2008 \\
\hline 23 & "Afilan hachas en defensa del Parque Cultural Ex Cárcel" & La Estrella & 25 de marzo 2008 \\
\hline 24 & $\begin{array}{l}\text { "Vestidos de negro y ensangrentados marcharon los artistas } \\
\text { de la ex cárcel" }\end{array}$ & La Estrella & 27 de marzo 2008 \\
\hline 25 & "Recinto ex Cárcel es desmantelado" & $\begin{array}{l}\text { El Mercurio de } \\
\text { Valparaíso }\end{array}$ & 28 de marzo 2008 \\
\hline 26 & "El añorado centro cultural" & La Estrella & 01 de abril 2008 \\
\hline 27 & "Presentan recurso por desalojo de ex Cárcel" & $\begin{array}{l}\text { El Mercurio de } \\
\text { Valparaíso }\end{array}$ & 03 de abril 2008 \\
\hline 28 & "Carta a Oscar Niemeyer" & $\begin{array}{l}\text { El Mercurio de } \\
\text { Valparaíso }\end{array}$ & 09 de abril 2008 \\
\hline 29 & "Corte de apelaciones porteña ordenó abrir la ex Cárcel” & La Estrella & 10 de abril 2008 \\
\hline 30 & "Fallo frena desalojo de la ex Cárcel" & El Mercurio & 10 de abril 2008 \\
\hline 31 & "Indignación en ex Cárcel: les robaron puertas y ventanas" & La Estrella & 11 de abril 2008 \\
\hline 32 & "Corte mantiene desalojo de los ocupantes de ex Cárcel" & $\begin{array}{l}\text { El Mercurio de } \\
\text { Valparaíso }\end{array}$ & 11 de abril 2008 \\
\hline 33 & "Alerta por uso patrimonial" & $\begin{array}{l}\text { El Mercurio de } \\
\text { Valparaíso }\end{array}$ & 13 de mayo 2008 \\
\hline
\end{tabular}




\begin{tabular}{|c|l|l|l|}
\hline 34 & "Urgen la protección del polvorín" & $\begin{array}{l}\text { El Mercurio de } \\
\text { Valparaíso }\end{array}$ & 25 de mayo 2008 \\
\hline 35 & $\begin{array}{l}\text { "Definitivo, proyecto Niemeyer para ex Cárcel de Valparaíso } \\
\text { no va más" }\end{array}$ & $\begin{array}{l}\text { El Mercurio de } \\
\text { Valparaíso. }\end{array}$ & $\begin{array}{l}7 \text { de noviembre } \\
2008\end{array}$ \\
\hline 36 & $\begin{array}{l}\text { "Niemeyer está triste y decepcionado por fracaso del proyecto } \\
\text { Ex Cárcel". }\end{array}$ & $\begin{array}{l}\text { El Mercurio de } \\
\text { Valparaíso. }\end{array}$ & $\begin{array}{l}8 \text { de noviembre } \\
2008\end{array}$ \\
\hline 37 & "Proyecto de la Ex Cárcel vuelve a fojas cero" & La Estrella & $\begin{array}{l}29 \text { de noviembre } \\
2008\end{array}$ \\
\hline 38 & "Nuevo coordinador para proyecto Ex Cárcel" & $\begin{array}{l}\text { El Mercurio de } \\
\text { Valparaíso }\end{array}$ & $\begin{array}{l}15 \\
2008\end{array}$ \\
\hline
\end{tabular}

